Die Abstimmung vom 1. Juni über den Verfassungsartikel ist von grösster Bedeutung. Mit dieser Vorlage versucht das Parlament, sowohl die freie Arztwahl als auch die Qualität unserer medizinischen Versorgung auf dem Altar des wirtschaftlichen Wettbewerbs zu opfern. Diesem Vorhaben muss ein Riegel geschoben werden.

Mit seinen nachfolgenden Ausführungen zeigt der Leiter unseres Rechtsdienstes, Hanspeter Kuhn, auf, dass dieser Verfassungsartikelentwurf trotz der beruhigenden Beteuerungen der verschiedenen Befürworter schlicht und einfach zu einem Abbau in unserem Gesundheitssystem führen würde.
Bis zur Abstimmung werden wir Sie regelmässig über das Thema informieren und auf dessen verschiedene Aspekte eingehen. Diesen Urnengang können wir nur gewinnen, wenn wir die Bevölkerung davon überzeugen, dass bei dieser Vorlage ihre Interessen auf dem Spiel stehen.

Die von uns veröffentlichten Argumente müssen allen unseren Mitgliedern die Möglichkeit geben, den Standpunkt der Ärzteschaft bestmöglich zu vertreten und damit die Wirkung der Abstimmungskampagne zu verstärken, die wir in den kommenden Wochen lancieren werden.

Jacques de Haller, Präsident der FMH

\title{
Zur Abstimmung vom 1. Juni: Nein stimmen, um die freie Arztwahl zu erhalten!
}

Die Debatte im Parlament hat klargemacht, um was es in der Abstimmung über Artikel 117a der Bundesverfassung wirklich geht:

- «Zwei Eckzähne hat die Vorlage aber doch: Sie heissen Vertragsfreiheit und Monismus» (Ständerat Hans Altherr als Kommissionssprecher, 6. Dezember 2007).

- «Wir stellen fest, dass hier handstreichartig quasi alle gesundheitspolitischen Provokationen kumulativ umgesetzt werden sollen, ohne dass sorgfältig dafür gearbeitet worden wäre» (Nationalrätin Jacqueline Fehr als Kommissionssprecherin unmittelbar vor der Schlussabstimmung, 17. Dezember 2007).

Auch die Voten der Fraktionssprecher lagen im wesentlichen auf derselben Linie.

Mit anderen Worten: Wenn Volk und Stände am 1. Juni 2008 Ja sagen würden, erteilten sie dem Gesetzgeber den Auftrag, die freie Arztwahl abzuschaffen und die monistische Spitalfinanzierung einzuführen. Nach dem heutigem Stand des Irrtums führte dies praktisch zwangsläufig dazu, dass die Kantone ihre bisherigen Spitalsubventionen an die Kassen überweisen - und dann gilt auch fürs Spital: «Wer zahlt, befiehlt!»

$\mathrm{Zu}$ Recht hat die NZZ so kommentiert: «Die Gegner wiesen vergeblich darauf hin, dass der wettbewerbsorientierte Gegenvorschlag auch in der vom Ständerat leicht abgeschwächten Form höchst umstrittene Elemente wie die Vertragsfreiheit und eine monistische Finanzierung enthalte» (NZZ, 18. Dezember 2007: «Gegenvorschlag zur Prämiensenkungsinitiative steht»).

Der Verfassungstext, der schöne Worte wie Qualität und Wirtschaftlichkeit im Titel führt, erweist sich bei ehr- licher Betrachtung als Wolf im Schafspelz - auch wenn Befürworter ihn vermutlich als Schaf im Schafspelz* zu verkaufen versuchen werden.

Das Ende der freien Arztwahl für die Patienten bedeutet auch: Wer als Versicherter jahrzehntelang mit seinen Prämien anderen die freie Arzt- und Spitalwahl ermöglicht hat, kann in Zukunft nicht mehr frei wählen, wenn er selbst krank wird. Damit würde ein Generationenvertrag gebrochen.

Die FMH setzt sich mit Überzeugung für die Förderung von Managed Care und weiteren zukunftsweisenden Lösungen für eine kostenverträgliche und für alle zugängliche Gesundheitsversorgung ein. Mit ManagedCare-Ärztenetzen kann die Behandlungsqualität zu vernünftigen Kosten optimiert werden. Managed Care muss aber für alle Beteiligten freiwillig bleiben - denn staatlicher Zwang zerstört die nötige Vertrauensbeziehung zwischen Arzt und Patient im Netzwerk.

Deshalb braucht es eine staatlich geregelte Auffanglösung für die Patienten und Ärzte, die nicht Managed Care wählen. Der Staat muss regeln, in welchem Spital und bei welchem Arzt sich der Patient behandeln lassen kann diese Frage darf man nicht den Kassen überlassen; mit der Einführung der Vertragsfreiheit würde man aber genau dies tun. Darum ist am 1. Juni 2008 in jedem Fall ein Nein in die Urne zu legen!

Hanspeter Kuhn, Fürsprecher, Leiter des Rechtsdienstes der FMH, stellvertretender Generalsekretär der FMH

* Als Schaf im Schafspelz hat Churchill seinerzeit den Oppositionsführer Clement Attlee tituliert. 